\title{
Assembly, Operation and Disassembly Manual for the Battelle Large Volume Water Sampler (BLVWS)
}

V. W. Thomas

R. M. Campbell

December 1984

Prepared for Lawrence Livermore National Laboratory under a Related Services Agreement with the U.S. Department of Energy Contract DE-AC06-76RLO 1830

Pacific Northwest Laboratory Operated for the U.S. Department of Energy by Battelle Memorial Institute 


\title{
DISCLAIMER
}

This report was prepared as an account of work sponsored by an agency of the United States Government. Neither the United States Government nor any agency thereof, nor any of their employees, makes any warranty, express or implied, or assumes any legal liability or responsibility for the accuracy, completeness, or usefulness of any information, apparatus, product, or process disclosed, or represents that its use would not infringe privately owned rights. Reference herein to any specific commercial product, process, or service by trade name, trademark, manufacturer, or otherwise, does not necessarily constitute or imply its endorsement, recommendation, or favoring by the United States Government or any agency thereof. The views and opinions of authors expressed herein do not necessarily state or reflect those of the United States Government or any agency thereof.

\author{
PACIFIC NORTHWEST LABORATORY \\ operated by \\ BATTELLE \\ for the \\ UNITED STATES DEPARTMENT OF ENERGY \\ under Contract DE-AC06-76RLO 1830
}

\begin{tabular}{|c|c|}
\hline \multicolumn{2}{|c|}{$\begin{array}{c}\text { Printed in the United States of America } \\
\text { Available from } \\
\text { National Technical Information Service } \\
\text { United States Department of Commerce } \\
5285 \text { Port Royal Road } \\
\text { Springfield, Virginia } 22161\end{array}$} \\
\hline & \\
\hline \multicolumn{2}{|c|}{ Printed Copy } \\
\hline Pages & $\begin{array}{l}\text { Price } \\
\text { Codes }\end{array}$ \\
\hline $001-025$ & $\mathrm{~A} 02$ \\
\hline $026-050$ & $\mathrm{AO3}$ \\
\hline $051-075$ & $A 04$ \\
\hline $076-100$ & A0S \\
\hline $101-125$ & $A 06$ \\
\hline $126-150$ & 107 \\
\hline $151-175$ & $\mathrm{~A} 0 \mathrm{~B}$ \\
\hline $176-200$ & $\mathrm{~A} 09$ \\
\hline $201-225$ & A010 \\
\hline $226-250$ & A011 \\
\hline $251-275$ & A012 \\
\hline $276-300$ & $\mathrm{~A} 013$ \\
\hline
\end{tabular}


ASSEMBLY, OPERATION AND DISASSEMBLY

MANUAL FOR THE BATTELLE LARGE VOLUME

WATER SAMPLER (BLVWS)

V. W. Thomas

R. M. Campbe11

December 1984

Prepared for

Lawrence Livermore National Laboratory under a Related Services Agreement with the U.S. Department of Energy

Contract DE-AC06-76RL0 1830

Pacific Northwest Laboratory Richland, Washington 99352 



\section{ABSTRACT}

Assembly, operation and disassembly of the Battelle Large Volume Water Sampler (BLVWS) are described in detail. Step by step instructions of assembly, general operation and disassembly are provided to allow an operator completely unfamiliar with the sampler to successfully apply the BLVWS to his research sampling needs. The sampler permits concentration of both particulate and dissolved radionuclides from large volumes of ocean and fresh water. The water sample passes through a filtration section for particle removal then through sorption or ion exchange beds where species of interest are removed. The sampler components which contact the water being sampled are constructed of polyvinylchloride (PVC). The sampler has been successfully applied to many sampling needs over the past fifteen years. 



\section{ACKNOWLEDGEMENTS}

The authors would like to express their gratitude to A. W. Madsen and E. N. Sullivan for machining the multitude of parts required for the current high volume water samplers and the many versions which preceded them. 



\section{CONTENTS}

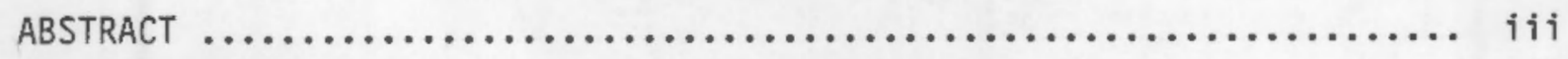

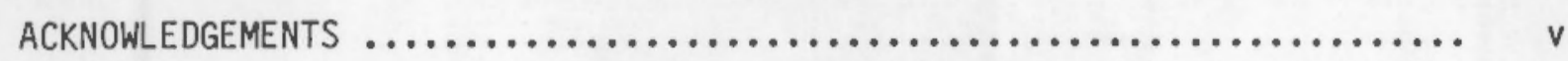

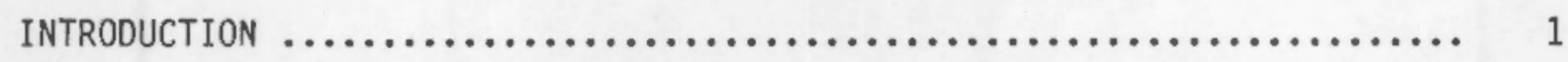

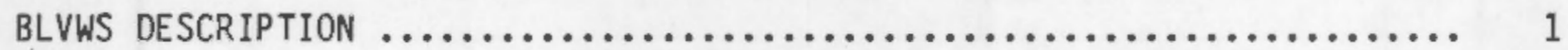

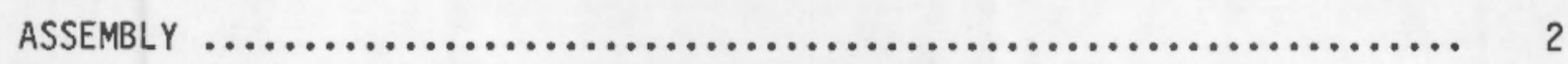

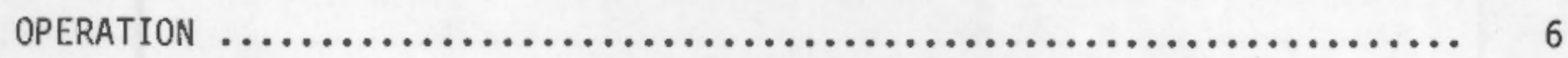

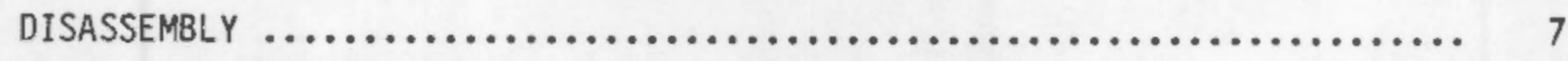

EXAMPLE APPLICATION $\ldots \ldots \ldots \ldots \ldots \ldots \ldots \ldots \ldots \ldots \ldots \ldots \ldots \ldots \ldots \ldots \ldots \ldots \ldots$

REFERENCES AND RELATED PUBLICATIONS $\ldots \ldots \ldots \ldots \ldots \ldots \ldots \ldots \ldots \ldots \ldots \ldots$ 



\section{FIGURES}

1 The Battelle Large Volume Water Sampler $\ldots \ldots \ldots \ldots \ldots \ldots \ldots \ldots \ldots$

2 Word Diagram of Battelle Large Volume Water

Sampler Âssembly ...................................... 4

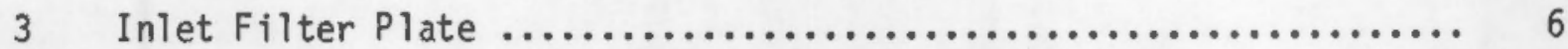

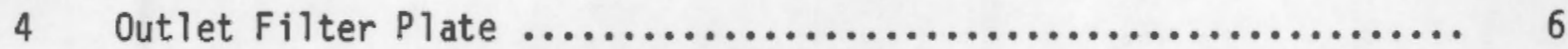

5 View of Slot Side of Inlet Filter Plate $\ldots \ldots \ldots \ldots \ldots \ldots \ldots \ldots . \ldots$

6 Blank PVC Plate (Slots in one Semicircle Not Shown) ........... 8

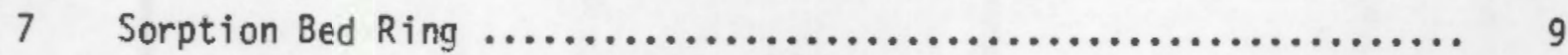

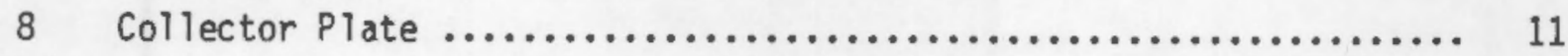





\section{INTRODUCTION}

It is often the dilemma of the researcher to find that a very large volume of water contains a very small fraction of the radionuclide he is interested in measuring. This presents the problem of concentrating the widely dispersed radionuclide of interest into a volume which can reasonably be handled for radiochemical or instrumental analysis. The Battelle Large Volume Water Sampler has been successfully employed for fifteen years to concentrate by filtration, ion exchange and sorption radionuclides of interest from thousands of liters of sample in relatively short periods of time.

Since the sampler was first reported in the literature (Silker, Perkins and Rieck 1971), several improvements and modifications have been made to the sampler, and numerous requests for instructions on assembly, operation and disassembly of the sampling units have been received. Therefore, the purpose of this report is to document these procedures and some modifications that have been incorporated into the sampler over the years. The sampling configuration of the units may vary in numbers of stages of each type (i.e. filtration, ion exchange, sorption). Therefore, although the instructions in this report were written for a sampler using eight parallel filters, a cation exchange resin bed, an anion exchange resin bed and an activated aluminum oxide sorption bed, additional or fewer stages of filtration might be added, and fewer or more exchange or sorption beds might be used, but the assembly, use and disassembly instructions with slight modifications for the numbers of times certain instructions are repeated would still be applicable.

\section{BLVWS DESCRIPTION}

The sampler is constructed entirely of polyvinyl chloride (PVC) with the exception of the aluminum end plates, the 8 steel support rods and the steel washers and nuts for the support rods. The sampler has been designed so that the water being sampled contacts only the PVC portions. Both inlet and outlet ports are located on the top (inlet on edge, outlet in center) for easy access. 
The water being sampled is pumped into a downward flowing inlet manifold located near one edge of the sampler. The water is directed through as many as 8 parallel $293 \mathrm{~mm}$ filters (on this particular sampler), and then into an upward flowing outlet manifold located near the opposite edge of the sampler from the inlet manifold. To increase filtering capacity, more parallel filter stages may be added by replacing the threaded rods with longer rods.

This manifold leads the water upward to a distribution plate which allows the water to be introduced evenly over the entire bottom surface of the first sorption bed. Up to $11 / 2$ to 2 inches of combined sorption bed thickness is possible with this sampler, although for most applications, each sorption bed is expected to be only from $1 / 4$ to $1 / 2$ inch in depth. PNL has used up to 4 inch thick beds, but with significantly reduced flow. The sorption beds are separated by filters of the same type used in the filtration section, but are strengthened by the addition of a "shark skin" support paper at the bottom of each sorption bed. The water exits through a central opening in an exit manifold at the top of the sampler. Figure 1 shows a photograph of an assembled BLVWS, and in schematic form a diagram of the general flow patterns through the sampler.

\section{$\underline{\text { ASSEMBLY }}$}

Let us assume that the sampler is completely disassembled for cleaning and we wish to reload it for operation using eight parallel filters, a cation exchange resin bed, an anion exchange resin bed, and an activated aluminum oxide sorption bed. Figure 2 is a word diagram of the assembly to be performed.

Care must be used to protect the mating surfaces of the sampler at all times from being cut, scratched or dented as damage to these surfaces will eventually result in water leaks.

Place the bottom aluminum plate with the attached threaded rods protruding upwards on a solid, level surface.

Although each individual plate of the sampler filtration section is numbered consecutively from the bottom up, and a "V" is milled into one side of the sampler for ease of identification and position verification, we have 

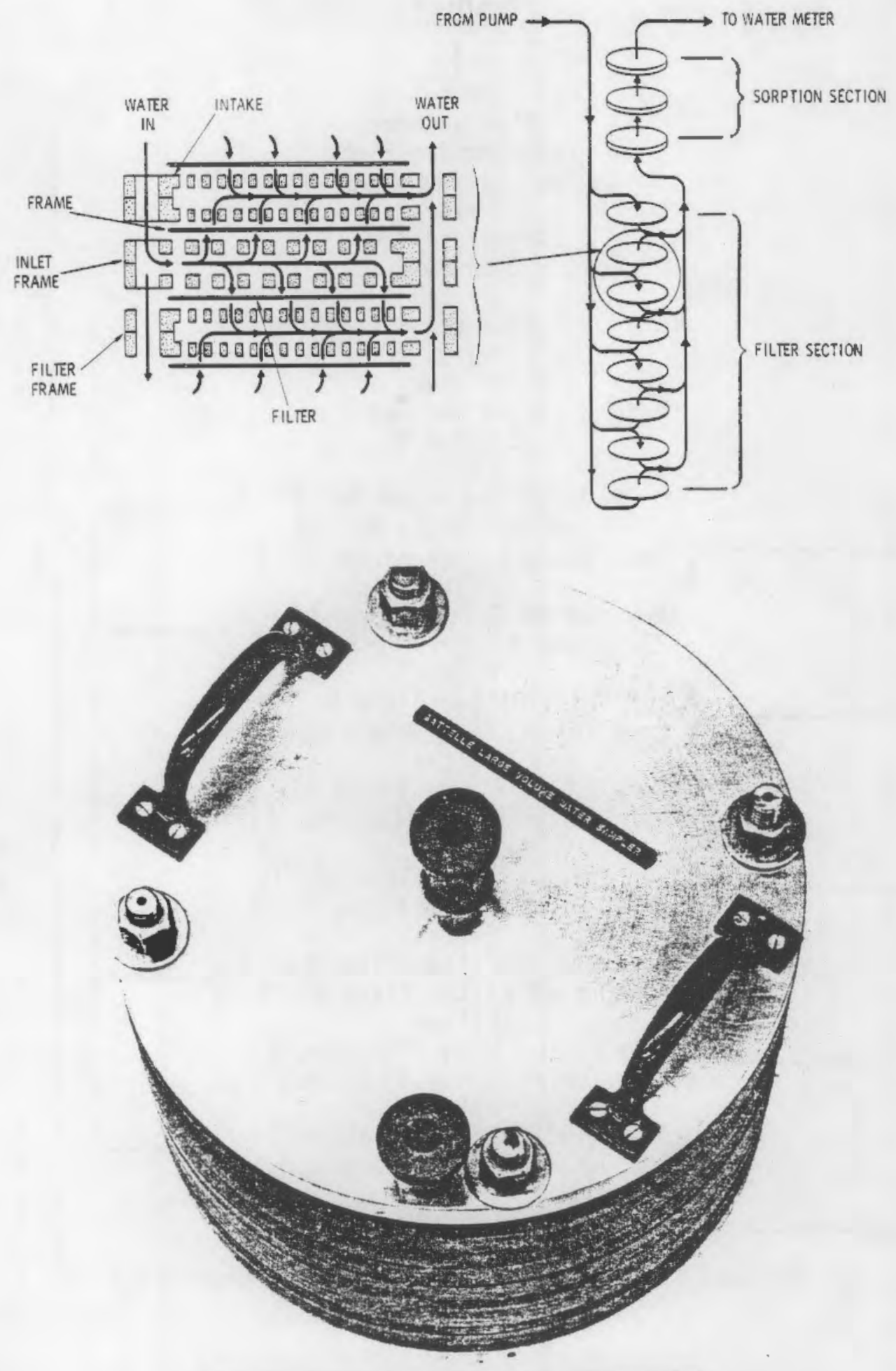

FIGURE 1. The Battelle large volume water sampler 


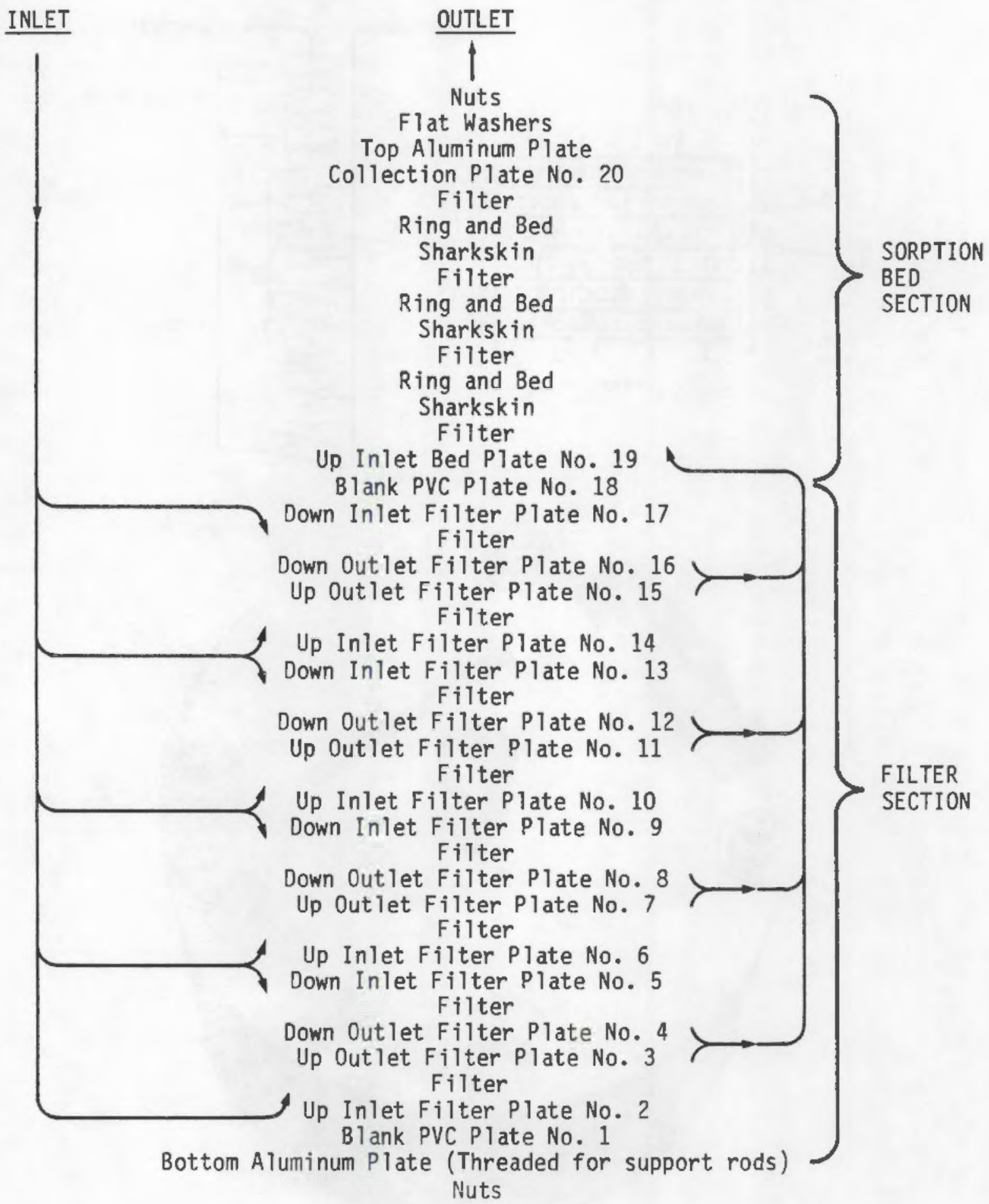

FIGURE 2. Word Diagram of Battelle Large Volume Water Sampler Assembly 
found it is beneficial to designate either one's left or right hand as the side on which to align the inlet holes, and then be consistent each time the sampler is assembled. Should weather conditions at sea be rough, or if lighting is poor during a particular assembly, the procedure will be much more efficiently completed.

1. Place blank PVC plate No. 1 over the rods being careful that the rods do not scratch the mating surface.

2. Place up-inlet filter plate No. 2 (Fig. 3) on top of plate No. 1 with the inlet hole and slots on your left, facing down and the $1 / 4$ inch concentric rings facing upwards.

3. Place a Millipore AP2029325 (or equivalent) filter on the concentric circles, being careful to center the filter to leave about a $3 / 8$ inch overlap of the filter all around the outside of the last concentric ring depression.

4. Place up-outlet filter plate No. 3 (Fig 4) on top of plate No. 2 slowly, to keep from dislodging the filter paper and allowing it to slip sidewise. The $1 / 16$ inch concentric rings should face down, and the outlet hole and slots should face up and be on your right. The inlet and outlet holes should align with the inlet and outlet holes of plate No. 2 .

5. Place down-outlet filter plate No. 4 (not shown) which is a mirror image of plate No. 3 on top of plate No. 3 with the outlet slots facing down and aligned with the slots on plate No. 3.

6. Center a Millipore filter on the $1 / 16^{\prime \prime}$ concentric rings.

7. Place down-inlet filter plate No. 5 carefully on top of plate No. 4 being careful to not dislodge the filter paper. Once again, the inlet slots are on the left and facing up while the concentric $1 / 4$ inch circles are down against the filter.

8. Place up-inlet filter plate No. 6 (Fig. 5) which is a mirror image of plate No. 5 on top of plate No. 5 with the holes and slots properly aligned, and concentric $1 / 4$ inch circles facing up.

9. This procedure is repeated, alternating pairs of outlet and inlet plates separated with Millipore filters until down-inlet filter 


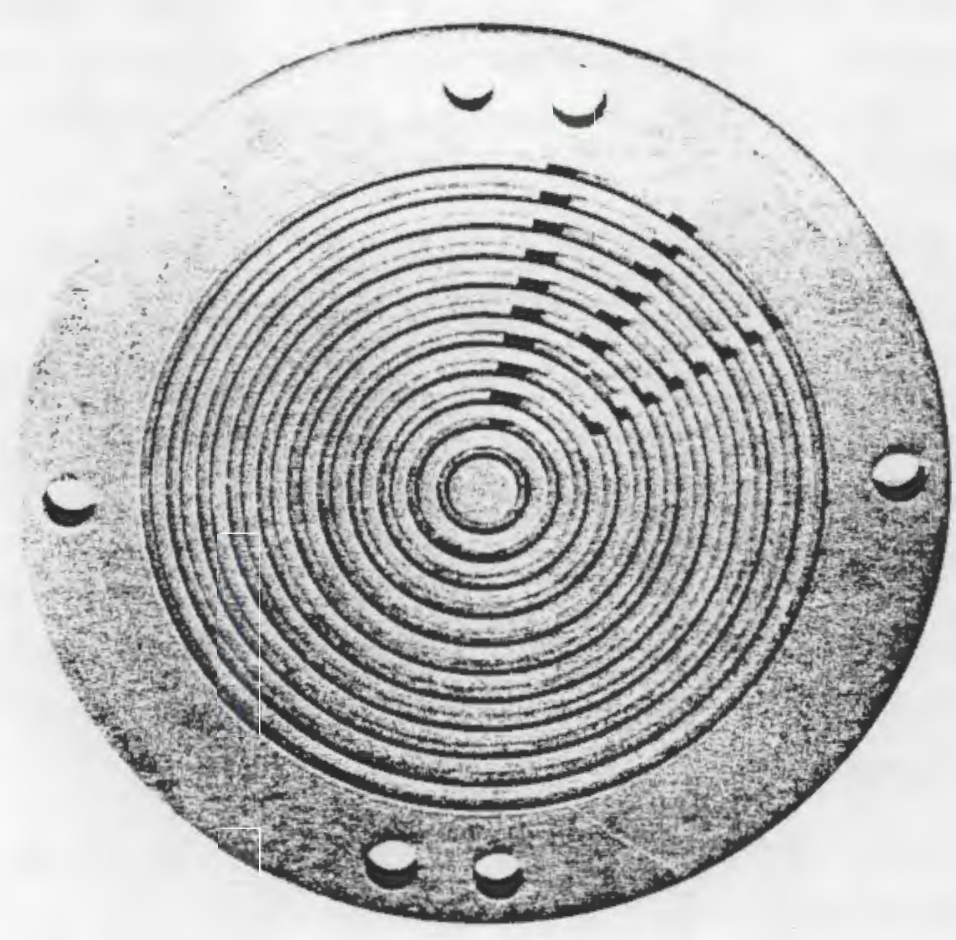

FIGURE 3. Inlet filter plate

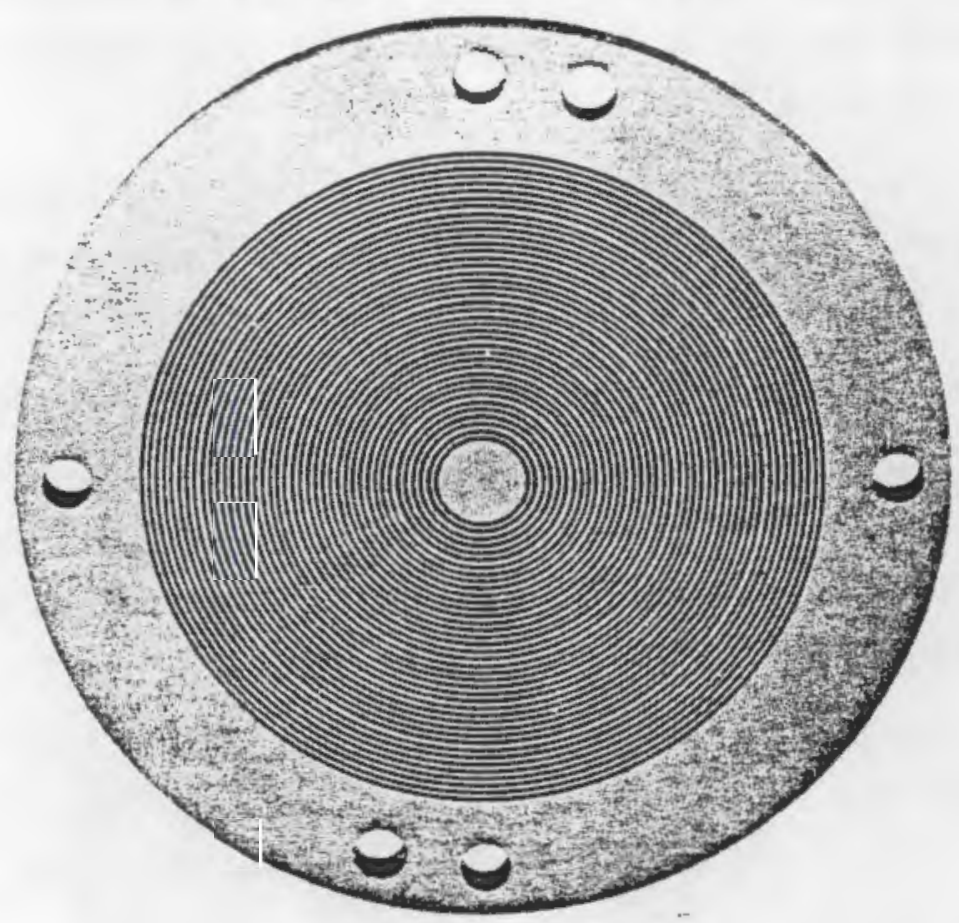

FIGURE 4. Outlet filter plate 


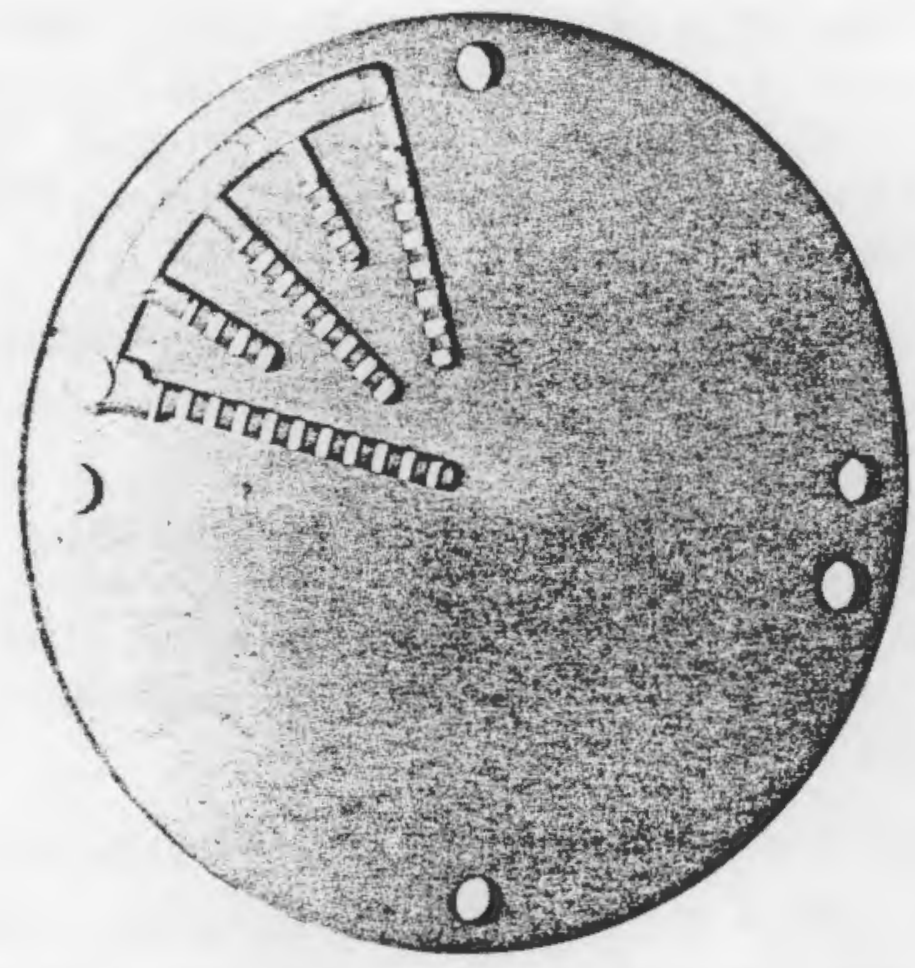

FIGURE 5. View of slot side of inlet filter plate

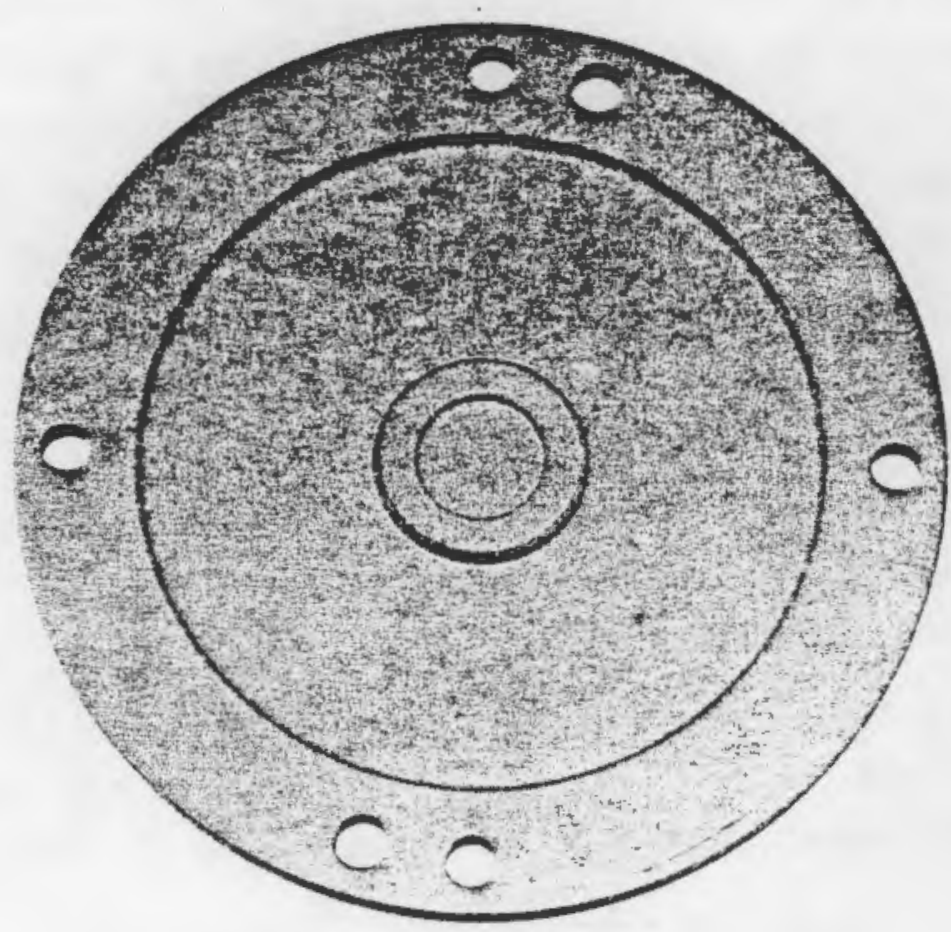

FIGURE 6. Blank PVC plate (slots in one semicircle not shown) 
plate No. 17 is in place.

10. Place blank PVC plate No. 18 (similar to Fig. 6 but with slots in one semicircle) on top of plate No. 17, assuring that the left and right inlet, outlet holes are properly oriented. The slots should feed the sorption beds with the outlet from the filter section, not raw water.

11. Place up-inlet sorption plate No. 19 on top of plate No. 18 with the $1 / 16$ inch concentric circles facing up and the inlet hole and slots facing down and aligned with the outlet hole of the filtration section. Although the orientation of this plate is the same as has been used for other plates with $1 / 16$ inch concentric rings, its purpose has been changed from a filter outlet plate to a sorption bed inlet plate. For assistance in alignment, plates 17, 18 and 19 have been screwed together as one unit.

12. Center a Millipore filter paper on top of plate No. 19.

13. Center a $290 \mathrm{~mm}$ "Shark Skin"(1) (or equivalent) filter paper on top of the Millipore filter paper.

14. Select a sorption bed ring (Fig. 7) the same thickness as desired for the cation resin bed. Place it on top of plate No. 19 assuring that the hole in the edge for inlet down to the filtration section is properly oriented on your left to allow unobstructed downward flow to feed unfiltered water to the filtration manifold. Note that sorption bed rings are not numbered since they may be used as singles or in different combinations dependent upon the chemistry required by the sampling experiment.

15. Empty a pre-weighed portion of cation exchange resin onto the center of the Shark Skin exposed through the sorption ring. (Pre-weighed portions of sorption materials increase field-loading efficiency.)

16. Using a straight edge (12" ruler or piece of $1 / 4$ inch thick aluminum), distribute the resin evenly in the ring depression and screen the surface smooth, flat and flush with the top surface of the ring.

(1) $29 \mathrm{~cm}$ "Shark Skin" paper manufactured by Schleicher and Schuell may be obtained from VWR Scientific (Catalog No. 28314-162). 


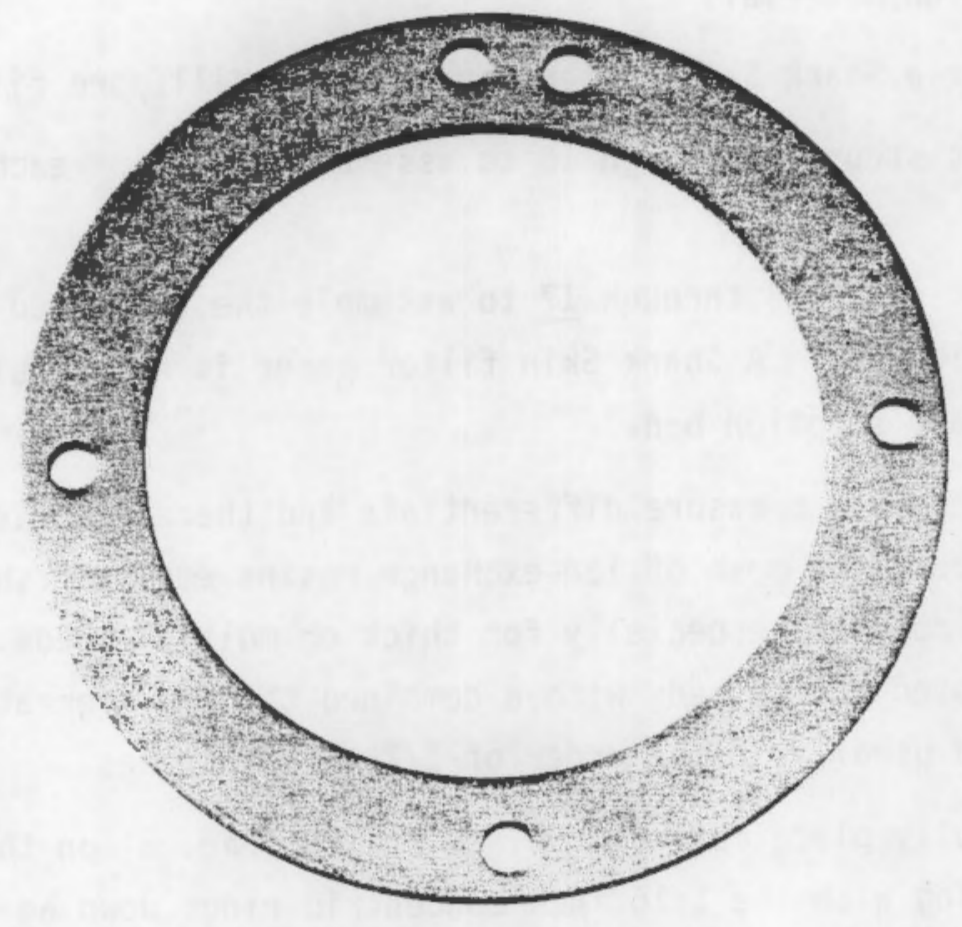

FIGURE 7. Sorption bed ring 
Clean the mating surface of the ring thoroughly to eliminate beads of resin from interfering with the seal formed with the next ring (usually gentle blowing by mouth is sufficient, but a rubber bulb and small brush may be of help).

17. Center a Millipore filter paper on the cation resin bed, being careful not to disturb the resin. Check the mating surface again for sorption material.

18. Center a Shark Skin filter paper on the Millipore filter paper.

19. Repeat steps 14 through 18 to assemble the anion exchange resin bed.

20. Repeat steps 14 through 17 to assemble the activated alumina(2) sorption bed. A Shark Skin filter paper is not required on top of the last sorption bed.

In order to keep pressure differentials and therefore flow rates within reasonable bounds, the mesh of ion-exchange resins employed should generally be 100 mesh or coarser, especially for thick or multiple beds. We have usually not attempted to use beds with a combined thickness greater than 1 to 1 $1 / 2$ inches, and usually in the order of $1 / 2$ to $3 / 4$ inches.

21. Carefully place collector plate No. 20 (Fig. 8) on the top sorption bed ring with the $1 / 16$ inch concentric rings down against the filter paper, and the inlet hole for unfiltered water properly aligned on the left.

22. Install the top aluminum plate fitted with $3 / 4$ inch PVC pipe fittings with the edge inlet fitting lined up with the inlet hole. The center fitting is the outlet to be connected to the inlet of a $3 / 4$ inch Rockwell water meter or equivalent. The collector plate and aluminum top plate assembly has been fastened together for convenience.

23. Place a flat washer and nut on each threaded rod, and finger tighten all nuts. The nuts must be tightened in several stages using a crisscross sequence similar to that used when mounting an automobile

(2) Activated alumina manufactured by Woelm, 70-290 mesh, neutral may be obtained from Universal Scientific, Inc., Atlanta, GA. The technical contact there is Dr. Mark Moskovitz. 


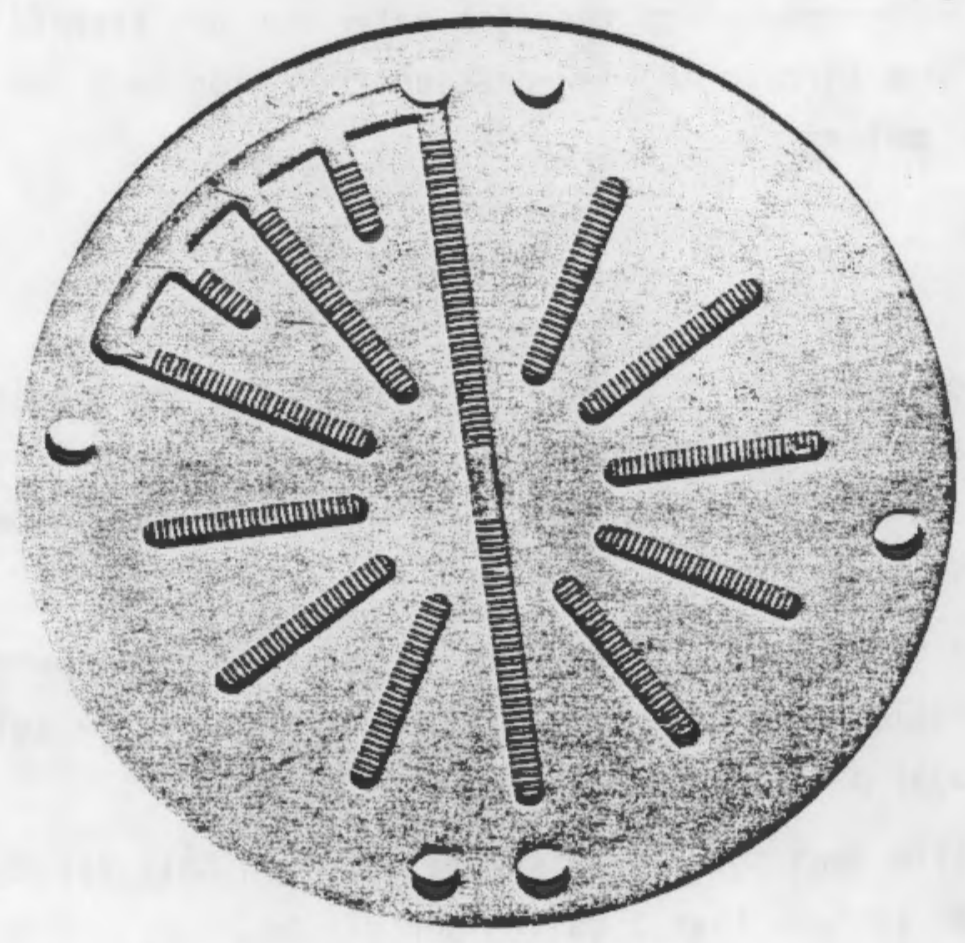

FIGURE 8. Collector plate 
tire to eliminate distortion of the plates which will result in leaks. The final torque required for a sampler with clean, smooth mating surfaces is approximately 50 to 70 foot-pounds. Further tightening, although immediate leaking may be reduced, will probably result in distortion of the plates requiring excessive tightening in future assemblies. Small leaks between plates are invariably on the pressure side in the filtration stages. Although messy, they may be ignored since the lost water has not been filtered, and has not gone through the low-pressure sorption beds nor the downstream water meter.

\section{OPERATION}

The use of $3 / 4$ inch PVC unions to connect the inlet hose and exit hose allows rapid assembly and disassembly. A $3 / 4$ inch PVC ball valve serves to control inlet water to the sampler. The inlet hose should be weighted to at least 25 pounds for shipboard sampling.

1. After the sampler has been fully assembled, but before the inlet and outlet hoses have been attached, turn on the self-priming, centrifugal pump(3) until the pump is primed.

2. Throttle down the flow with the $3 / 4$ inch ball valve on the pump outlet to less than 1 gallon per minute.

3. Allow the water to run into the sampler inlet without pressure until the water flows out of the outlet. Look for evidence of resin or alumina in the effluent indicating breakthrough of the Milliporeshark skin filter papers or gross leaks. Certain resins may slightly discolor the water for a short while, but the absence of resin beads will indicate proper performance.

4. Connect the inlet coupling securely to the sampler, and physically lift the sampler and gently rock from side to side to eliminate air bubbles and assure that the filters and sorption materials are thoroughly wet. Watch ihe effluent for sorption materials throughout

(3) We recommend a minimum $1 / 3 \mathrm{HP}$ to $1 / 2 \mathrm{HP}$ pump with a $40 \mathrm{gpm}$ capacity (a) $0 \mathrm{ft}$ head which should deliver $10 \mathrm{gpm}$ a $20 \mathrm{ft}$ head. 
this preparation.

5. Connect the outlet hose of the sampler to the water meter.

6. Slowly increase the flow by opening the PVC ball valve slowly, until the optimum sampling flow of $2 \mathrm{gpm}$ is achieved.

7. In particularly dirty water, the pressure differential across the filter bank may increase too rapidly to allow collection of enough sample. A pre-filter may have to be installed ahead of the sampler using a few filter stages of another BLVWS to be changed periodically, or some other pre-filtering arrangement may be used. PNL has successfully used several types of prefilters including "CUNO" types and standard swimming pool filters to help clarify muddy fresh water.

\section{DISASSEMBLY}

Upon completion of sampling, shut the ball valve, turn off the pump and disconnect the outlet and inlet unions. Carefully tip the sampler so that the water can run out of the ports. After draining, disassemble as follows:

1. Once again using a crisscross sequence, loosen the top nuts and remove the nuts and washers.

2. Carefully lift the aluminum top plate and set aside.

3. Lift the collector plate No. 20 slowly while checking that the sorption bed is not stuck to the bottom of it, and set aside (remember to protect mating surfaces from damage).

4. Remove top Millipore filter.

5. Remove sorption bed ring while scraping clinging sorption material from ring onto bed.

6. Roll up Shark Skin with sorption material and transfer to labelled sample container.

7. Repeat steps 4 through 6 for the other two beds.

8. Disassemble the filtration section and thoroughly clean for the next sampling. Running water will usually clean the surfaces, but a nylon brush may be helpful to dislodge stubborn material. 
This technique will allow the collection of two 1000 gallon samples per 24 hour period per sampler. The 2 gallon per minute flow rate has been determined from experience to give the least physical problems, and yet also be sufficient to collect large samples. Lower flow rates have been used, and on one occasion up to 7.6 gallons per minute were sampled under emergency conditions, but this is not generally recommended.

Sampling should be performed with the minimum lift possible to reduce pump load. A rough maximum pumping height (without a submersible pump) is about $15 \mathrm{feet}$, and on board ship, this may have to be lower because the roll of the ship may cause the lift to vary from 10 to 20 feet.

\section{EXAMPLE APPLICATION}

The following procedure is included as an example of one way in which the aluminum oxide sorption bed may be pre-treated to enhance collection of certain radionuclides. The following procedure has been successfully used to pre-treat aluminum oxide to remove greater than 90 per cent of the natural radium isotopes from sea water (Perkins 1969b). Two beds are used in series to allow the efficiency of radium removal to be estimated from inspection of the ratio of radium collected in each bed.

1. In 4-liter beakers $1 / 2$ full of $\mathrm{Al}_{2} \mathrm{O}_{3}$, cover the $\mathrm{Al}_{2} \mathrm{O}_{3}$ with a saturated solution of 420 grams per liter sodium sulfate ( $\left.\mathrm{Na}_{2} \mathrm{SO}_{4}\right)$. Stir and let stand for 1 hour.

2. Filter into 4-liter beakers retaining the $\mathrm{Na}_{2} \mathrm{SO}_{4}$ solution for reuse and cover the $\mathrm{Al}_{2} \mathrm{O}_{3}$ with a saturated solution of $87 \mathrm{~g} / 1$ iter barium nitrate $\left(\mathrm{Ba}\left(\mathrm{NO}_{3}\right)_{2}\right)$. Stir and let stand for 1 hour.

3. Filter into 4-liter beakers and cover once again with the saturated $\mathrm{Na}_{2} \mathrm{SO}_{4}$ solution. Stir and let stand for 1 hour.

4. Wash the $\mathrm{Al}_{2} \mathrm{O}_{3}$ three times with 2 liters of distilled water stirring well, and filtering between each wash cycle.

5. Air dry the $\mathrm{A}_{2} \mathrm{O}_{3}$ on plastic sheeting with heat lamps at 15 to 20 inches elevation.

6. Weigh into plastic bags or bottles in aliquots of the required size to prepare sorption beds of the proper thickness in the BLVWS. 


\section{REFERENCES AND RELATED PUBLICATIONS}

Crecelius, E. A., D. E. Robertson, K. H. Abel, D. A. Cochran and W. C. Weimer. 1978. Marine Chemistry of Energy-Generated Pollutants-Efficiency Evaluation of the Battelle Large Volume Water Sampler. PNL-2500, Pacific Northwest Laboratory, Richland, Washington.

Perkins, R. W. 1969a. $51 \mathrm{Cr}$ From the Columbia River in Ocean Water off the West Coast During November, 1968. 8NWL-1051, Pacific Northwest Laboratory, Richland, Washington.

Perkins, R. W. 1969b. Radium and Radiobarium Measurement in Sea-water and Freshwater by Sorption and Direct Multidimensional Gamma-ray Spectrometry. BNWL-1051, Pacific Northwest Laboratory, Richland, Washington.

Silker, W. B. 1968. "Beryllium-7 in Ocean Water." Science (161):879.

Silker, W. B. 1969. Surface Concentrations of Radionuclides in the North Pacific 0cean. BNWL-1051, Pacific Northwest Laboratory, Richland, Washington.

Silker, W. B. and H. G. Rieck. 1969. Radionuclide Concentration in the Atlantic Ocean Near Barbados. BNWL-1051, Pacific Northwest Laboratory, Richland, Washington.

Silker, W. B., R. W. Perkins and H. G. Rieck. 1971. "A Sampler for Concentrating Radionuclides from Natural Waters." Ocean Engineering (2):49-55. Pergamon Press. Printed in Great Britain.

Silker, W. B. 1972a. "Beryllium-7 and Fission Products in the GEOSECS II Water Column and Applications of Their Oceanic Distributions." Earth and Planetary Science Letters (16):131-137. North-Holland Publishing Company.

Silker, W. B. 1972b. "Horizontal and Vertical Distribution of Radionuclides in the North Pacific Ocean." J. Geophysical Research (77) No. 6:1061-1070. 

PNL -5325

UC -11

\section{DISTRIBUTION}

No of

Copies

OFFSITE

Robert W. Buddemeier

Nuclear Chemistry Division

Lawrence Livermore National

Laboratory

P. 0. Box 808

Livermore, CA 94550

K. Marsh

Nuclear Chemistry Division

Lawrence Livermore National

Laboratory

P. 0. Box 808

Livermore, CA 94550

27 DOE Technical Information

Center

ONSITE

DOE Richland Operations Office

H. E. Ransom

37 Pacific Northwest Laboratory

N. A. Wogman (5)

D. E. Robertson

R. M. Campbell (5)

V. W. Thomas (10)

J. C. Laul

M. R. Smith

K. H. Abel

P. 0. Jackson

L. J. Kirby

E. A. Lepel

H. G. Rieck

C. W. Thomas

J. A. Young

Publishing Coordination (2)

Technical Information (5)

Distr. -1 


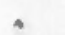

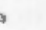

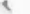

. 